\title{
THE EFFECT OF HIGH ENERGY MILLING ON THE SR-HEXAFERRITE NANOCRYSTALLINE POWDER SYNTHESIZED BY A SOL-GEL AUTOCOMBUSTION METHOD
}

\author{
S. SADEGHI-NIARAKI \\ Center of Excellence in Magnetic Materials, School of Metallurgy and Materials, University of Tehran, \\ Tehran 11155 4563, Iran \\ somayeh.sadeghi@gmail.com

\section{S. A. SEYYED EBRAHIM ${ }^{\mathrm{a}}$} \\ Center of Excellence in Magnetic Materials, School of Metallurgy and Materials, University of Tehran, \\ Tehran 11155 4563, Iran \\ saseyyed@ut.ac.ir

\section{SH. RAYGAN} \\ Center of Excellence in Magnetic Materials, School of Metallurgy and Materials, University of Tehran, \\ Tehran 11155 4563, Iran \\ shraygan@ut.ac.ir
}

\begin{abstract}
In this research $\mathrm{SrFe}_{12} \mathrm{O}_{19}$ nanocrystalline synthesized by sol-gel auto-combustion method and subsequent annealing at $1000^{\circ} \mathrm{C}$ for $1 \mathrm{~h}$ subjected to mechanochemical treatment in a high-energy ball mill and then re-annealing. A planetary ball mill (Fritsch Pulveristte 6) was used to mill the strontium hexaferrite powder at $300 \mathrm{rpm}$ in air for 10,20 and 40 hours. The process was studied by $\mathrm{X}$-ray diffraction technique and scanning electron microscopy. The X-ray study showed that $\mathrm{SrFe}_{12} \mathrm{O}_{19}$ phase was decomposed by milling. Strontium hexaferrite and $\gamma$ - $\mathrm{Fe}_{2} \mathrm{O}_{3}$ were obtained with 10 hours milling. There were $\alpha-\mathrm{Fe}_{2} \mathrm{O}_{3}$ and strontium hexaferrite in XRD patterns of 20 hours milled sample. With increasing of the milling time to 40 hours, strontium hexaferrite was decomposed completely. The annealing of the 20 and $40 \mathrm{~h}$ milled powders at $900^{\circ} \mathrm{C}$ for $1 \mathrm{~h}$ led to the formation of single phase strontium hexaferrite with smaller crystallite size compare to that of the hexaferrite powder before milling and subsequent annealing.
\end{abstract}

Keywords: High-Energy Milling; Sol-Gel Auto-Combustion; Sr-Hexaferrite; Nanocrystalline.

\footnotetext{
${ }^{\text {a }}$ Corresponding Author
} 


\section{Introduction}

The hexagonal M-type ferrite, $\mathrm{SrFe}_{12} \mathrm{O}_{19}$, has been studied intensively for many years due to their importance as permanent magnets and high-density magnetic recording media. Some of these technological applications require materials with a strict control of homogeneity, particle size and shape. The preparation method strongly determines its magnetic and structural properties. ${ }^{1}$

Various preparation techniques, such as sol-gel method, ${ }^{2}$ sol-gel auto-combustion method, ${ }^{3}$ hydrothermal technique, ${ }^{4}$ co-precipitation method ${ }^{5}$ and mechanical alloying, ${ }^{6}$ are used to produce nanoparticles of this material.

Mechanochemical treatment by high energy ball milling is now recognized as a powerful tool for the synthesis of the materials, like amorphous alloys, nanocrystalline metals and alloys and ceramic materials. ${ }^{7}$

In this paper, the effect of different milling processes on the activation of the powder synthesized by sol-gel auto combustion method was investigated. This activation not only reduced the formation temperature of the hexaferrite, but also resulted in a decrease in the size of the final product.

\section{Experimental}

$\mathrm{Fe}(\mathrm{NO} 3) .9 \mathrm{H} 2 \mathrm{O}, \mathrm{Sr}(\mathrm{NO} 3) 3$ and citric acid were used as starting materials. The sol prepared by a proper ratio of metal nitrates and citric acid. $\mathrm{pH}$ was adjusted at 7 by adding ammonia to the sol. Then the sol was heated on a hot plate with continuous stirring to evaporate the water. With more heating, the sol converted to a gel and by heating the gel it was automatically burnt and a porous product was obtained. The combustion product was then calcined at $1000^{\circ} \mathrm{C}$ in air for $1 \mathrm{~h}$ to obtain single phase Strontium hexaferrite. ${ }^{8}$

A planetary ball mill (Fritsch Pulveristte 6) was used to mill the strontium hexaferrite at $300 \mathrm{rpm}$ in air atmosphere for 10, 20 and 40 hours. The ball to powder ratio was adjusted at 20 and steel balls with 10 and $20 \mathrm{~mm}$ diameter was used for milling.

The resultant as-milled powder samples were subjected to characterization afterwards. X-ray powder diffraction patterns of all the samples were taken on a Phillips X'pert using Co K $\alpha$ radiation. The morphology of the samples was studied by scanning electron microscopy (CamScan MV2300, PHILIPS XL30) technique.

\section{Results and Discussion}

Fig. 1 shows the X-ray diffraction patterns of the as-burnt powder before and after calcination at $1000^{\circ} \mathrm{C}$. It can be seen that the different phases in the as-burnt powder were $\gamma-\mathrm{Fe}_{2} \mathrm{O}_{3}, \mathrm{SrCO}_{3}$ and $\alpha-\mathrm{Fe}_{2} \mathrm{O}_{3}$ while the calcined powder was the single phase of strontium hexaferrite. The average crystallite size of the calcined sample calculated as 40nm using Scherrer formula.

Fig.2 shows the morphology of the as-burnt powders calcined at $1000^{\circ} \mathrm{C}$. SEM micrographs of this sample exhibit particles of Sr-hexaferrite with nano average size. 
Fig. 3 shows the XRD patterns of the samples milled for 10, 20 and 40 hours. This figure indicates that strontium hexaferrite have been decomposed after milling. These results are in good agreement with the results reported by the other investigators. ${ }^{7}$

It is seen from Fig. 3a that strontium hexaferrite and $\gamma-\mathrm{Fe}_{2} \mathrm{O}_{3}$ were obtained with 10 hours milling.

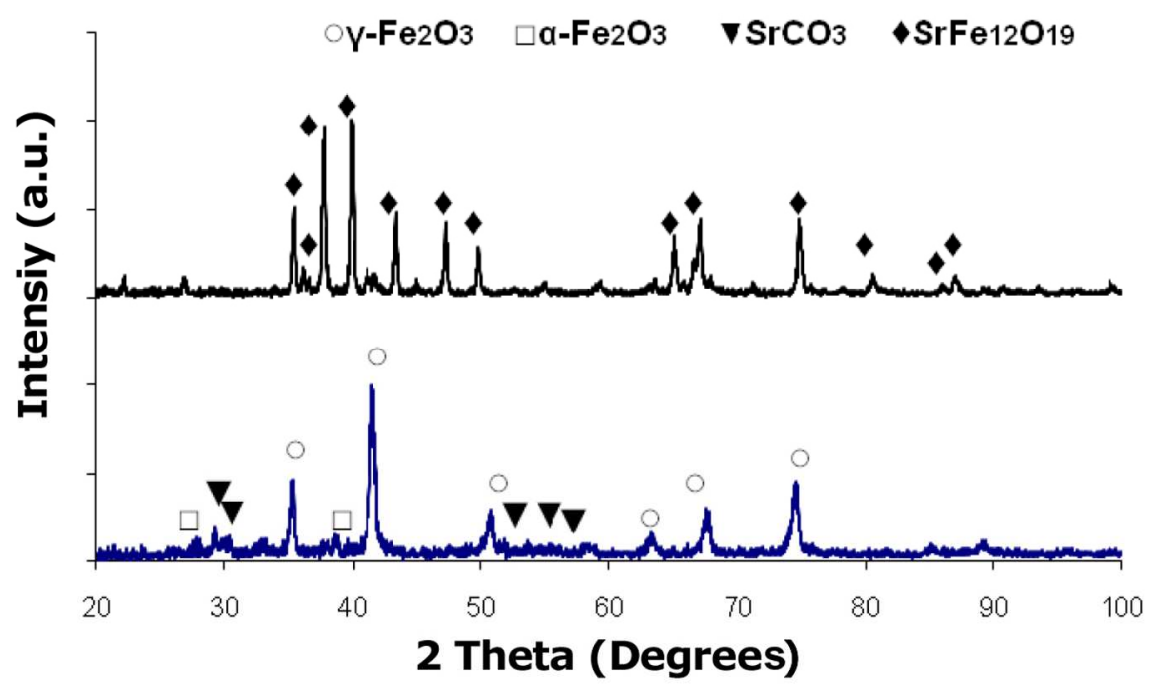

Fig. 1. XRD patterns of the as-burnt powder a) before and b) after calcination at $1000^{\circ} \mathrm{C}$.

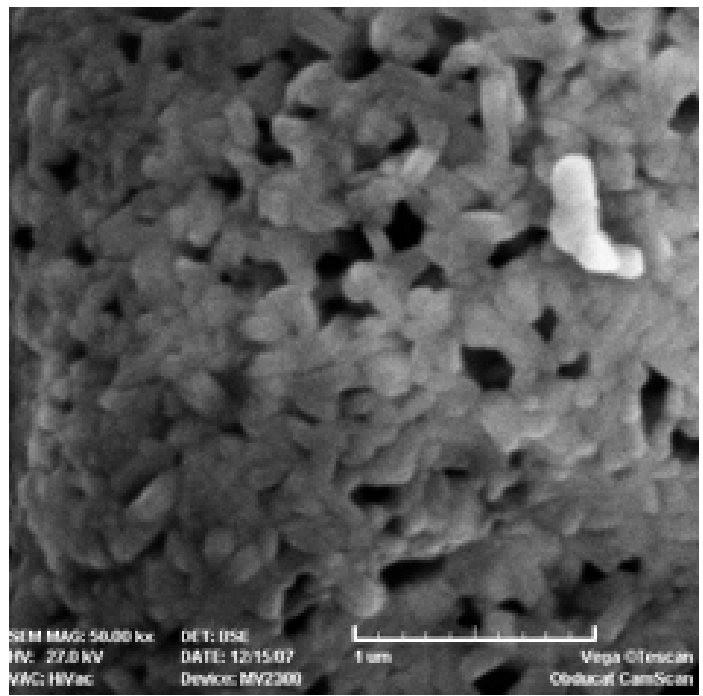

Fig 2. SEM micrograph of the as-burnt powders calcined at $1000^{\circ} \mathrm{C}$. 
There are $\alpha-\mathrm{Fe}_{2} \mathrm{O}_{3}$ and strontium hexaferrite in XRD patterns of 20 hours milled sample (Fig.3b). Hsiang et al. ${ }^{9}$ reported that mechanical treatment of $\gamma-\mathrm{Fe}_{2} \mathrm{O}_{3}$ powders could be an attractive method for the production of nano-size and equiaxed $\alpha-\mathrm{Fe}_{2} \mathrm{O}_{3}$ powders. Mechanical treatment increased the number of particle contacts, which could be acted as nucleation sites for the $\gamma \rightarrow \alpha-\mathrm{Fe}_{2} \mathrm{O}_{3}$ phase transformation and resulted in decreasing the transformation temperature. With increasing of the milling time to 40 hours, strontium hexaferrite was decomposed completely (Fig.3c).

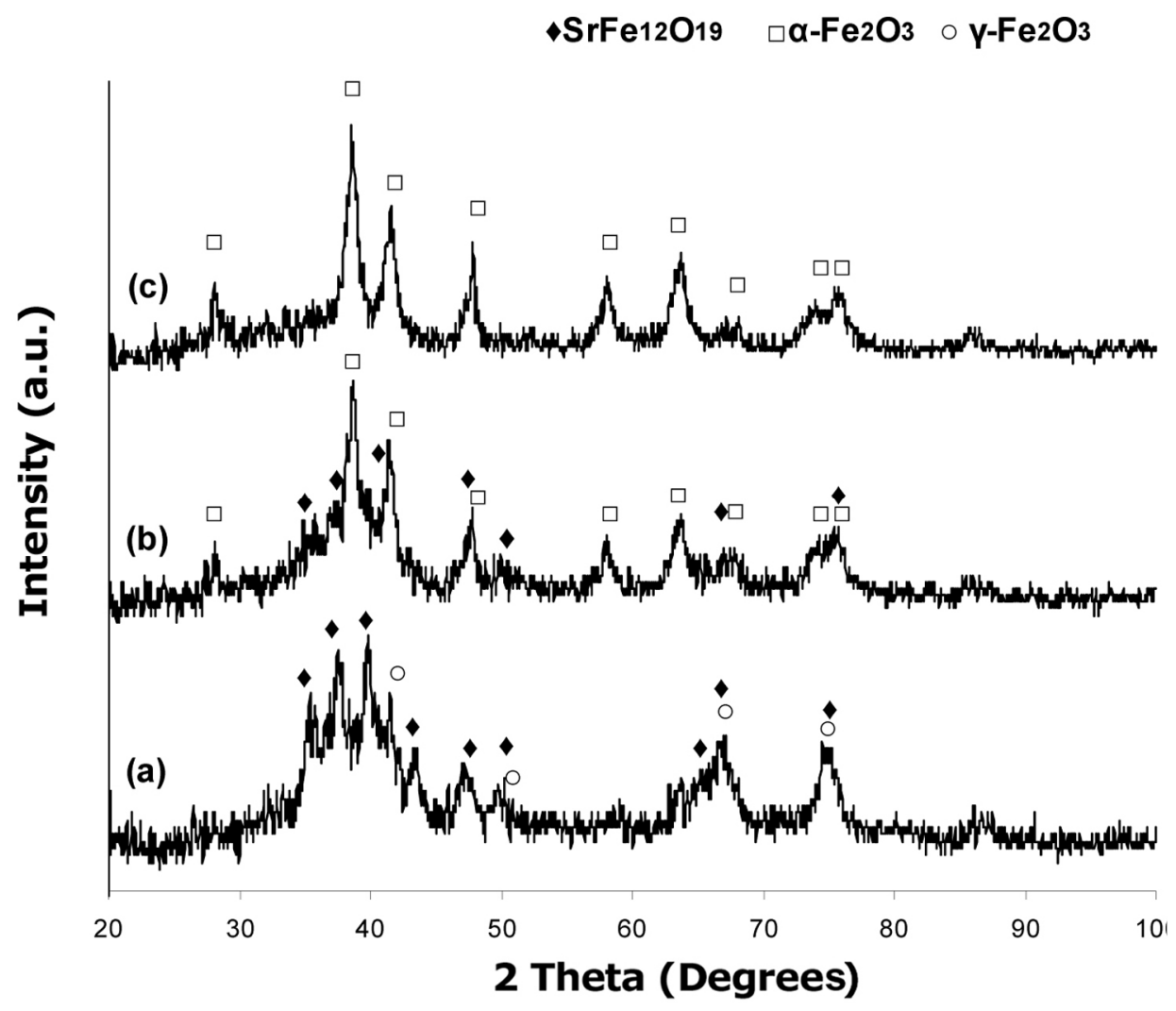

Fig3. XRD patterns of the samples milled for a) 10, b) 20 and c) 40hours.

Fig. 4 shows SEM micrographs of the milled samples. In this figure, fine particles with narrow particle size distribution are observed in $10 \mathrm{~h}$ milled sample. In $20 \mathrm{~h}$ milled sample some particles were agglomerated. It seems that agglomerated particles were separated them after $40 \mathrm{~h}$ milling.

The Milled samples were calcined at $900^{\circ} \mathrm{C}$ for obtaining the single phase strontium hexaferrite. Fig. 5 shows the XRD patterns of these samples. The patterns confirm the formation of single phase Sr hexaferrite only after 20 and 40 hours milling. The mean 
crystallite size of the sample milled for 20 hours before calcination were calculated 34 $\mathrm{nm}$. So it is clear that the milling and subsequence annealing of strontium hexaferrite resulted in smaller crystallite size (Table. 1). SEM micrographs of this samples is also shown in Fig. 6.
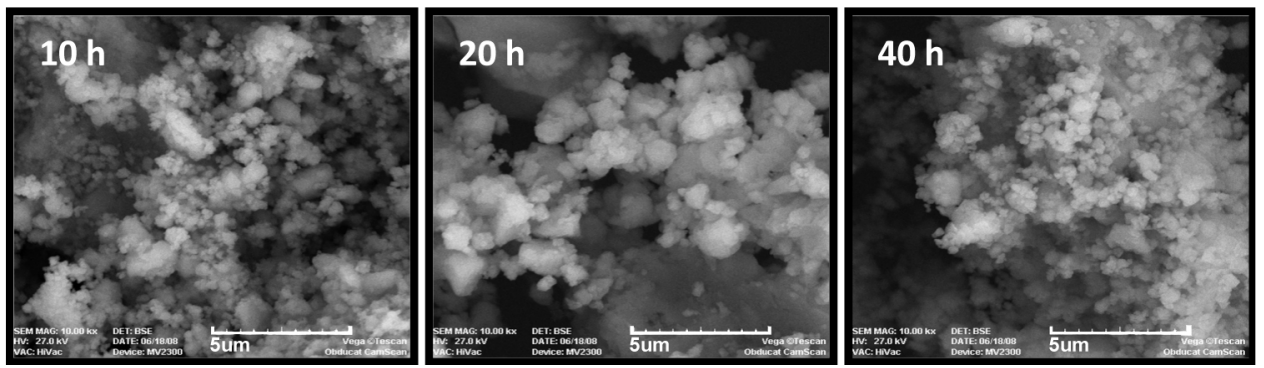

Fig 4. SEM micrographs of milled samples for 10, 20 and 40 hours.

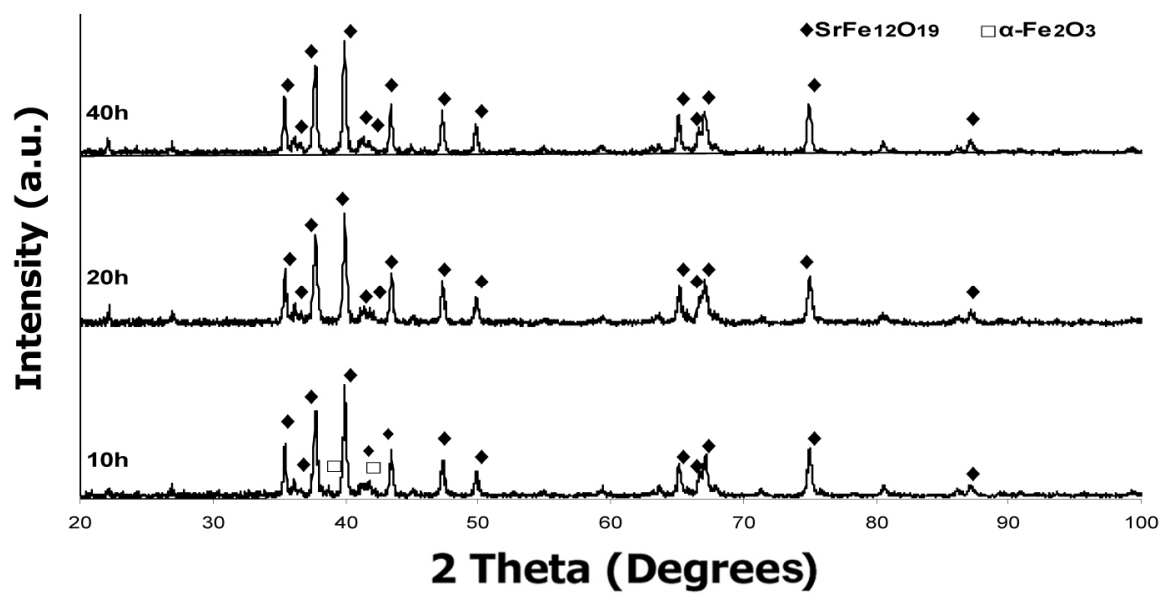

Fig 5. XRD patterns of the samples milled for different times and then calcined at $900^{\circ} \mathrm{C}$.

Table 1. Comparison of the crystallite size between the initial calcined sample and this sample after $20 \mathrm{~h}$ milling and re-calcination.

\begin{tabular}{lc}
\hline \multicolumn{1}{c}{ Sample } & Crystallite size (nm) \\
\hline $\begin{array}{l}\text { The as burnt powder calcined at } 1000^{\circ} \mathrm{C} \\
\begin{array}{l}\text { The calcined powder milled for } 20 \text { hours and re- } \\
\text { calcined at } 900^{\circ} \mathrm{C}\end{array}\end{array}$ & $30 \mathrm{~nm}$ \\
\hline
\end{tabular}




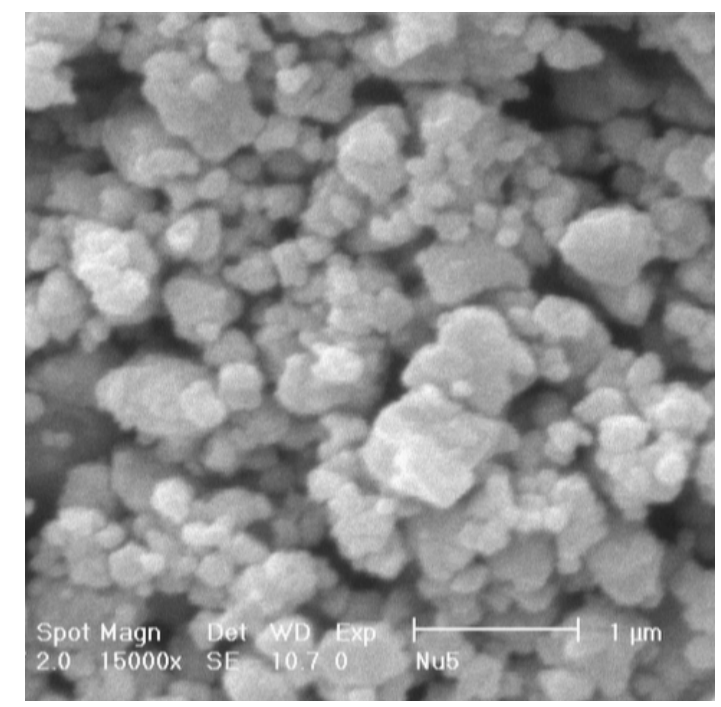

Fig. 6. SEM micrograph of the samples milled for 20 hours and then calcined at $900^{\circ} \mathrm{C}$

\section{Conclusions}

1- Mechanical treatment resulted in decomposition of strontium hexaferrite.

2- After $10 \mathrm{~h}$ milling $\gamma-\mathrm{Fe}_{2} \mathrm{O}_{3}$ and $\mathrm{Sr}$-hexaferrite traces were observed in XRD patterns.

3- 20h milling resulted in transformation of $\gamma-\mathrm{Fe}_{2} \mathrm{O}_{3}$ to $\alpha-\mathrm{Fe}_{2} \mathrm{O}_{3}$.

4- After 40h milling, strontium hexaferrite was decomposed completely.

5- The single phase strontium hexaferrite was formed again with calcination of the milled samples at $900^{\circ} \mathrm{C}$ for $1 \mathrm{~h}$.

6- The mean particle size of the Sr-hexaferrite obtained after post calcination of the milled Sr-hexaferrite is smaller than the initial Sr-hexaferrite before milling process.

\section{References}

1. R. Martinez Garcia, E. Reguera Ruiz, E. Estevez Rams, R. Martinez Sanche, J. Mag. Mag Mat., 223, 133-137 (2001).

2. G. Mu, X. Pan, N. Chen, K. Gan, M. Gu, Mat. Res. Bult., 43, 1369-1375, (2008).

3. M. R. Barati, S. A. Seyyed Ebrahimi, R. Dehghan, IEEE Trans. Mag., 45(6), 2561-2564 (2009).

4. D. Mishara, S. Anand, R. K. Panda and R. P. Das, Mat. Chem. Phys., 1-5 (2004).

5. R. Dehghan, S.A. Seyyed Ebrahimi, A. Badiei, J. Non-Cryst. Sol., 354, 5186-5188 (2008).

6. S. V. Ketov, Yu. D. Yagogkin, A. L. Lebed, Yu. V. Chernopyatova, K. Khlopkov, J. Mag. Mag. Mat., 300, 479-481 (2006).

7. M.E. Rabanal, A. Varez, B. Levenfeld, J.M. Torralba, J. Mat. Proc. Tech., 143-144, 470-474 (2003).

8. S. Alamolhoda, S. A. Seyyed Ebrahimi, A. Badiei, J. Phys. Met. Met., 102, S71-S73, (2006).

9. H. I. Hsiang, F. S. Yen, Ceram. Int., 29, 1-6 (2003). 